\title{
COMPARISON THE DYE REMOVAL ACTIVITY OF SYSTEMS CONTAINED SURFACTANTS AND FUNGUS
}

\author{
$\ddot{U} L K \ddot{U} Y E D U D U G \ddot{U} L, G \ddot{O N U ̈ L} D O ̈ N M E Z *$
}

Ankara University, Faculty of Science, Department of Biology, 06100 Beşevler-Ankara, Turkey

(Received: November 18, 2011 - Accepted: February 23, 2012)

\begin{abstract}
ABSRACT
Dye decolorization ability of the systems contained only $R$. arrhizus, only cationic surfactants and both of them were studied. The optimal $\mathrm{pH}$ (3-7), initial dye $(50-800 \mathrm{mg} / \mathrm{L})$ and surfactant concentration $(0.5$ and $1 \mathrm{mM})$ for Alkythrimethyl ammonium bromide $(\mathrm{CTAB})$ was determined in three days incubation period and the difference of Remazol Blue dye removal activity between Dodecylthrimethyl ammonium bromide (DTAB), Hegzadecylthrimethyl ammonium bromide $(\mathrm{HTAB})$ and CTAB was identified. In the surfactant effect experiments it was observed that maximum dye removal activity occured in the system contained both fungus and $0.5 \mathrm{mM} \mathrm{CTAB}$ as, $77.52 \%$, while the dye removal activity of only fungus and only CTAB were $21.2 \%$ and $71.2 \%$ in $100 \mathrm{mg} / \mathrm{L}$ dye concentration. The optimal conditions for dye removal were $\mathrm{pH} 5$, low initial dye concentratios such as $100 \mathrm{mg} / \mathrm{L}$ and $1 \mathrm{mM} \mathrm{CTAB}$ concentration at the end of three days incubation period and the $95.4 \%$ dye removed by the sytem contained both fungus and CTAB. The dye removal activiy of the system contained fungus and cationic surfactants (DTAB, CTAB and HTAB) was compaired in the same optimal conditions and observed that maximum dye removal occured in the system that contained fungus and $1 \mathrm{mM} \mathrm{HTAB}$, as $98.4 \%$. The systems that contained surfactant and fungus are new approcahes for effective dye removal from textile effluents. According to this study, the CMC of surfactant is an important issue to increase dye removal efficiency.
\end{abstract}

Keywords: Decolorization, Surfactant, R. arrhizus, Remazol Blue

\section{INTRODUCTION}

Dyes are large and important group of chemical pollutants for aquatic ecosystem because of their toxicity and carsinogenicity ${ }^{1,2}$. The treatment of effluents containing dyes, which come mainly from textile industries, is a challenging issue among environmental technologies ${ }^{3}$. Traditional wastewater treatment technologies have proven to be significantly ineffective for removal of synthetic textile reactive dyes from wastewater because of the chemical stability of these pollutants ${ }^{4}$. Biological treatments present a relatively inexpensive way to remove dyes from wastewater ${ }^{5}$. There are some reports that represented the efficient removal capacity of dyes by the dead $R$. arrhizus biomass $6,7,8,9$.

Surfactants are surface active compounds that reduce the surface tension and interfacial tension. A surfactant monomer consits of a hyrophilic head and a hydrophobic tail ${ }^{10}$. Surfactant monomers form micelles in solutions when they reached Critical Miscelle Concentration (CMC). CMC is the minimum concentration required to initiate micelle formation ${ }^{11}$. Surfactants are widely used in industrial applications such as raw materials purification process in mining and petrolium industry, chemical process in cosmetic, pharmaceutic and food industry ${ }^{12}$ and dyeing process in textile industry ${ }^{13}$. Therefore dyeing effluent contains both surfactants and dyes.

Some methods are developed to achive high dye removal efficiencies by using surfactants as modfying adsorbent or surfactant impregnated montmorillonite ${ }^{14,15}$. The effect of Dodecyl thrimethyl ammonium bromide surfactant on dye decolorization activity of $R$. arrhizus was studied ${ }^{16}$. However there is not any study about compairing dye removal activity of systems contained only surfactant, only fungus and both surfactant and fungus. In addition to this there is not any explanation about the different behavior of different cationic surfactants in dye removal activity.

The goal of this work was to explain the different effect of Dodecylthrimethyl ammonium bromide (DTAB), Alkylthrimethyl ammonium bromide (CTAB) and Hegzadecylthrimethyl ammonium bromide (HTAB) on removal of Remazol Blue by living fungal strain Rhizopus arrhizus at batch scale level. Also it is intended to use low-cost media such as molasses which is a waste ptroduct of sugar refineries in this study. Molasses was the main carbon source in the study and widely used as a substrate in microbial fermentations. To our knowledge this is the first report showing the different dye removal activity behavior of cationic surfactants beacuse of their structural difference.

\section{EXPERIMENTAL}

\section{Preparation of dye and surfactant solutions}

The cationic surfactants Alkyltrimethyl ammonium bromide (CTAB) $\left(\mathrm{C}_{14} \mathrm{H}_{29} \mathrm{~N}\left(\mathrm{CH}_{3}\right)_{3} \mathrm{Br}, \mathrm{MW}: 333.37 \mathrm{~g} / \mathrm{mol}\right)$ and Hexadecyltrimethylammonium bromide (HTAB) $\left(\mathrm{C}_{16} \mathrm{H}_{33} \mathrm{~N}\left(\mathrm{CH}_{3}\right)_{3} \mathrm{Br}\right.$, MW: $\left.364.46 \mathrm{~g} / \mathrm{mol}\right)$ were supplied by Sigma. Dodecyltrimethyl ammonium bromide (DTAB) $\left(\mathrm{C}_{12} \mathrm{H}_{22} \mathrm{~N}_{\left(\mathrm{CH}_{3}\right)} \mathrm{Br}\right.$,
MW: $308.34 \mathrm{~g} / \mathrm{mol}$ ) was obtained from Fluka. Stock surfactant solutions were prepared from surfactant, at $1.0 \mathrm{~g} / \mathrm{L}$ concentration by dissolving weighed amount in double-distilled water. Remazol Blue was obtained from Aytemizler Textile Co. in pure form. The dye stock solution was prepared by dissolving the powdered dyestuff in distilled water to a final concentration of $2 \% \mathrm{w} / \mathrm{v}$. Appropriate volumes of the stock solutions were added to the media.

\section{Microorganism and growth conditions}

The filamentous fungus Rhizopus arrhizus, was obtained from the US Department of Agriculture Culture Collection, was used in this study. The microorganism was cultivated in liquid molasses media. The composition of the molasses medium is as follows: beet molasses solution (approximately equivalent to $10 \mathrm{~g} \mathrm{l}^{-1}$ sucrose), $1.0 \mathrm{~g} / \mathrm{L}\left(\mathrm{NH}_{4}\right)_{2} \mathrm{SO}_{4}, 0.5 \mathrm{~g} / \mathrm{L} \mathrm{KH}_{2} \mathrm{PO}_{4} .{ }^{17}$. The $\mathrm{pH}$ was adjusted to desired value with $1 \mathrm{M} \mathrm{NaOH}$. The medium was autoclaved $\left(121^{\circ} \mathrm{C}\right.$ for $\left.15 \mathrm{mins}\right)$ and then a defined quantity of dye and surfactant solution with a known concentration was added to the growth medium.

The fungal cells were inoculated into experiment tubes contained $5 \mathrm{ml}$ media and incubated in 2 days at $30 \pm 1{ }^{\circ} \mathrm{C}$ then the activated fungal biomass transferred in to $250 \mathrm{~mL}$ Erlenmeyer flasks containing $100 \mathrm{~mL}$ of molaless medium with adequate dye and surfactant concentration at $30 \pm 1{ }^{\circ} \mathrm{C}$ in three days incubation period.

\section{Decolorization and microbial growth assays}

To examine the effect of surfactant on decolorization, the cultures were grown in the molasses medium contained $100 \mathrm{mg} / \mathrm{L}$ dye (Remazol Blue) and supplied with $0.5 \mathrm{mM}(166.7 \mathrm{mg} / \mathrm{L}) \mathrm{CTAB}$ and without CTAB at $\mathrm{pH} 5$.

The effect of initial $\mathrm{pH}$ on the dye decolorization activity of systems contained only fungus, only surfactant and both of them was investigated at $\mathrm{pH} 3,4,5,6,7$ in the molasses medium supplied with $100 \mathrm{mg} / \mathrm{L}$ dye (Remazol Blue $)$ and $0.5 \mathrm{mM}(166.7 \mathrm{mg} / \mathrm{L})$ CTAB. The fungal cells were acclimated in the media that contained surfactant by transferring twice before measuring dye removal and $2 \mathrm{~mL}$ of activated culture was inoculated into $100 \mathrm{~mL}$ of molasses media.

To determine the effect of initial dye concentrations on dye decolorization of the systems contained molasses medium with 50, 100, 200, 400 and 800 $\mathrm{mg} / \mathrm{L}$ dye and $0.5 \mathrm{mM}(166.7 \mathrm{mg} / \mathrm{L}) \mathrm{CTAB}$ in the absence and presence of fungus.

In order to determine the surfactant that have different sutructure effect on decolorization, three surfactants, named Dodecyltrimethyl ammonium bromide (DTAB) $\left(\mathrm{C}_{12} \mathrm{H}_{22} \mathrm{~N}\left(\mathrm{CH}_{3}\right)_{3} \mathrm{Br}\right.$, MW: $\left.308.34 \mathrm{~g} / \mathrm{mol}\right)$, Alkyltrimethyl ammonium bromide $(\mathrm{CTAB})\left(\mathrm{C}_{14} \mathrm{H}_{29} \mathrm{~N}\left(\mathrm{CH}_{3}\right)_{3} \mathrm{Br}\right.$, MW: $\left.333.37 \mathrm{~g} / \mathrm{mol}\right)$ and Hexadecyltrimethyl ammonium bromide (HTAB) $\left(\mathrm{C}_{16} \mathrm{H}_{33} \mathrm{~N}\left(\mathrm{CH}_{3}\right)_{3} \mathrm{Br}\right.$, MW: $364.46 \mathrm{~g} / \mathrm{mol}$ ), were used. To examine the effect of different surfactants and their concentrations on bioremoval, $R$. arrhizus was inoculated into molasses media containing $0.5 \mathrm{mM}(166.7 \mathrm{mg} / \mathrm{L})$ and $1 \mathrm{mM}(333.4 \mathrm{mg} / \mathrm{L}) \mathrm{CTAB}$ 
surfactant, $0.5 \mathrm{mM}(154.2 \mathrm{mg} / \mathrm{L})$ and $1 \mathrm{mM}(308.4 \mathrm{mg} / \mathrm{L})$ DTAB surfactant, $0.5 \mathrm{mM}(182.2 \mathrm{mg} / \mathrm{L})$ and $1 \mathrm{mM}(364.46 \mathrm{mg} / \mathrm{L})$ HTAB surfactant and 100 $\mathrm{mg} / \mathrm{L}$ dye.

The effect of both initial surfactant (DTAB, CTAB and HTAB) concentrations on fungal growth was determined by measuring dry weight of fungus at the end of the incubation period.

Uninoculated Erlenmeyer flasks containing dye and surfactant were used as control samples to observe any reactions of the media with dye and surfactant. Each of these experiments and the measurements described below to follow the daily changes in the samples throughout the incubation period were performed in triplicate.

\section{Analytical methods}

During the incubation period, a $3 \mathrm{~mL}$ sample was taken daily from each flask and centrifuged at $10000 \mathrm{rpm}$ at 15 minutes to remove suspended biomass. The concentration of Remazol Blue was determined by measuring the absorbance at $600 \mathrm{~nm}$. Cell-free molasses medium was used as the blank. For the measurement of fungal growth, the biomass concentration was determined by measuring dry weight at the end of the incubation period. Dry weight of the fungal biomass was obtained by filtering the contents of each flask through pre-weighed filter paper, drying to a constant weight at $70{ }^{\circ} \mathrm{C}$ at one night and measuring the dry weight of biomass. Dry weight was expressed in terms of $g$ of biomass per liter of culture.

Absorbance measurements and centrifugation were performed using a Shimadzu UV 2001 model spectrophotometer and Med. Instruments MPW$351 \mathrm{R}$ model centrifuge, respectively.

The effect of surfactant on dye bioremoval properties and fungal growth of $R$. arrhizus were investigated in a batch system as a function of initial $\mathrm{pH}$, dye and surfactant concentrations.

The percentage bioremoval of dye was calculated from Eq. : Dye Decolorization $(\%)=\left(\mathrm{C}_{\mathrm{o}}-\mathrm{C}_{\mathrm{f}}\right) / \mathrm{C}_{\mathrm{o}} \times 100$

In this equation, $\mathrm{C}_{\mathrm{o}}$ and $\mathrm{C}_{\mathrm{f}}$ represent the initial and final dye concentrations $(\mathrm{mg} / \mathrm{L})$, respectively.

\section{RESULTS AND DISCUSSION}

\section{The effect of CTAB on dye removal}

The effect of CTAB on dye decolorization of culture was determined in the absence and presence of $0.5 \mathrm{mM} \mathrm{CTAB}$ with $100 \mathrm{mg} / \mathrm{L}$ dye in molasses medium at $\mathrm{pH}$ 5. The culture free flask contained molasses medium ( $\mathrm{pH} 5)$ with $0.5 \mathrm{mM} \mathrm{CTAB}$ and $100 \mathrm{mg} / \mathrm{L}$ dye was used as control. At the end of three days incubation period, the dye removal of the system that contained only $R$. arrhizus was $21.2 \%$ and only CTAB was $71.2 \%$. Maximum dye removal occured in the system that contained both fungus and CTAB, as $77.5 \%$ (Figure 1)

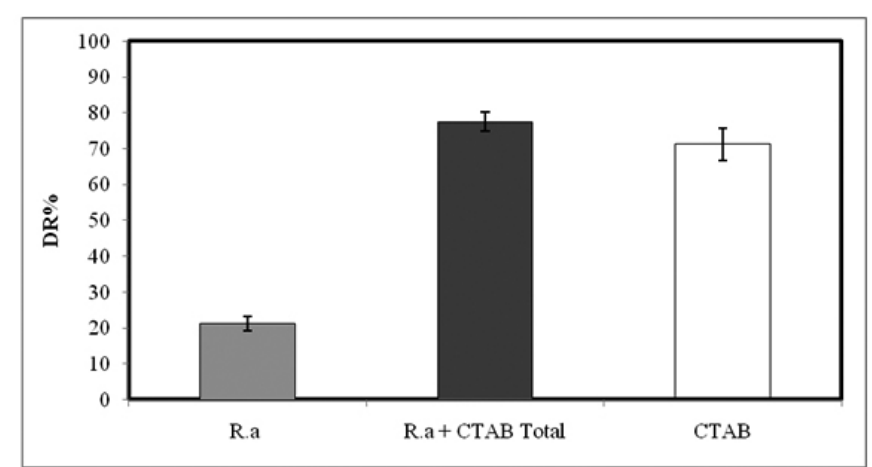

Fig. 1. The effect of surfactant on dye removal (DR \%) of Rhizopus arrhizus (R.a.) with $100 \mathrm{mg} / \mathrm{L}$ initial Remazol Blue concentration at $\mathrm{pH} 5$ (R.a: R. arrhizus without CTAB; R.a +CTAB: fungus with 0.5 mM CTAB; CTAB: $0.5 \mathrm{mM}$ Alkyl thrimethyl ammonium bromide without fungus; T: $30 \pm 1{ }^{\circ} \mathrm{C}$; incubation period: 3 days).

\section{The effect of $\mathrm{pH}$ on dye removal}

The effect of medial $\mathrm{pH}$ on dye removal of systems contained only $R$. arrhizus, only CTAB and both of them was examined in different medial $\mathrm{pH}$ values as 3, 4, 5, 6 and 7 in flasks contained $100 \mathrm{mg} / \mathrm{L}$ dye and $0.5 \mathrm{mM}$ CTAB concentrations. As seen on Figure 2 (a), removal activity of system that contained both $R$. arrhizus and CTAB (77.5\%) and only CTAB (71.2\%) was maximum at $\mathrm{pH}$ 5. A previous researh emphasized the importance of $\mathrm{pH}$ on microbial growth and the $\mathrm{pH}$ range of 4 to 5 was suitable condition for fungal growth and also microbial decolorization ${ }^{18}$. Maximum anionic dye removal activity of $R$. arrhizus was occured at low $\mathrm{pH}$ values because at acidic conditions fungal surface charged negatively and positive dye interaction on the surface was raised ${ }^{7,8,9}$. In this study it was observed that anionic dye decolorization activity of the system that contained only $R$. arrhizus was high (Fig. 2 a) but the fungal growth was disminished (Fig. 2 b) in low pH values such as 3 . The electrostatic interactions between the fungal surface and dye had more importance than fungal growth on dye removal. The maximum dye removal was observed at $\mathrm{pH} 5$ in the system that contained fungus and $\mathrm{CTAB}$. While the medial $\mathrm{pH}$ was raised, the fungal surface became negative and the new interactions occured between the fungal surface and cationic surfactant (CTAB). The anionic dye also interacted with $\mathrm{CTAB}$ and surfactant enhanced the dye availability of fungus at $\mathrm{pH}$ 5. The surfactant $\mathrm{CTAB}$ maintained the interactions between fungal surface and dye at $\mathrm{pH} 5$, which was also optimal $\mathrm{pH}$ value for fungal growth, and enhanced dye removal. The optimal $\mathrm{pH}$ was 5 for dye removal activity of system that contained fungus and CTAB.
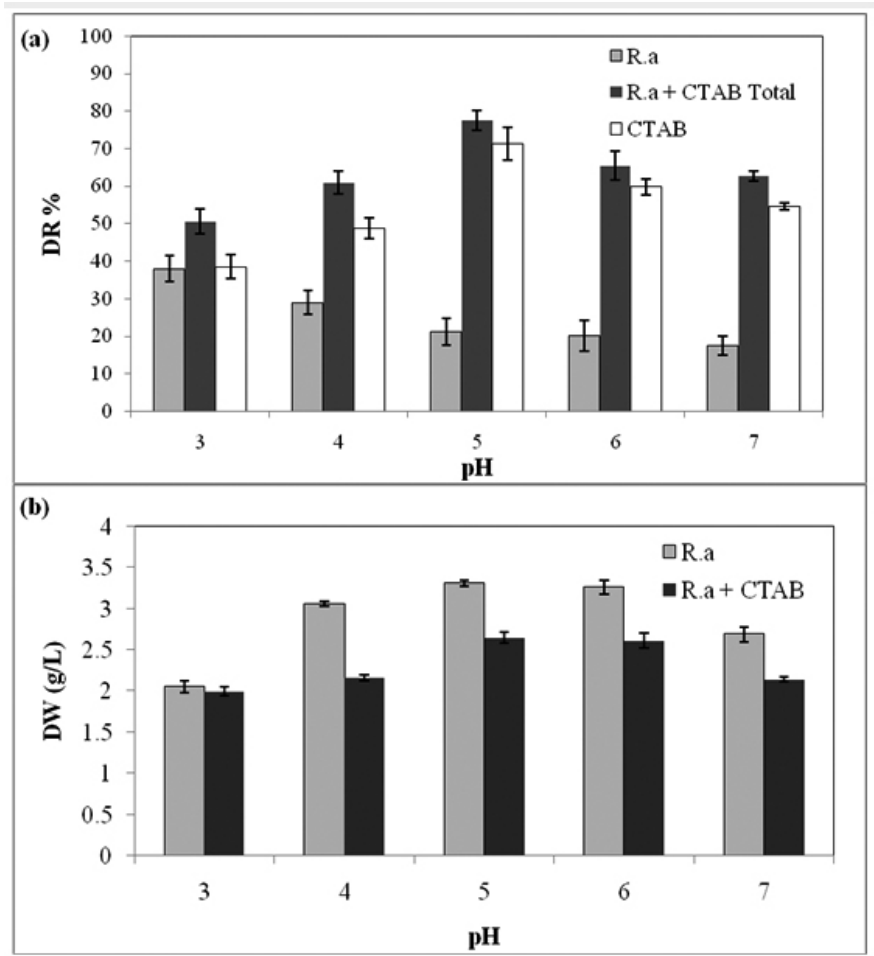

Fig. 2: (a) The effect of $\mathrm{pH}$ on dye removal (DR \%) with $100 \mathrm{mg} / \mathrm{L}$ initial Remazol Blue concentration (b) The effect of $\mathrm{pH}$ on fungal growth (dry weight, DW) with $100 \mathrm{mg} / \mathrm{L}$ initial Remazol Blue concentration (R.a.: Rhizopus arrhizus; R.a +CTAB: fungus with $0.5 \mathrm{mM}$ CTAB; CTAB: $0.5 \mathrm{mM}$ Alkyl thrimethyl ammonium bromide without fungus; $\mathrm{T}$ : $30 \pm 1{ }^{\circ} \mathrm{C}$; incubation period: 3 days).

\section{The effect of Remazol Blue concentration on dye removal}

The effect of the initial Remazol Blue concentration on dye decolorization was examined in the following series of experiments, in which initial dye concentrations were varied as $50,100,200,400$ and $800 \mathrm{mg} / \mathrm{L}$, whereas CTAB concentration was kept constant at $0.5 \mathrm{mM}$ at pH 5 in three days incubation period. As seen on Figure 3, in all dye concentrations dye removal activity of fungus and surfactant together were higher than only surfactant (CTAB) 
activity. The decolorization was decreased from low to high dye concentration in both systems. The agumentation of dye concentration dismissed the growth of yeast and caused a long lag period ${ }^{19}$.Increasing initial dye concentration resulted in decreasing biomass value during cultivation ${ }^{20}$. It is considered that high dye concentration negatively effect the fungal growth and decolorization. The surfactant dye decolorization activity was also inhibited by higher dye concentration (Fig. 3). Simoncic and Span (1998) have reported that there were electrostatic attractive interactions between the oppositely charged dyes and surfactants ${ }^{21}$. Electrostatic interactions between dye and surfactant created a complex in a certain level and in this complex opposite charged surfactant is used to recover dye from dye-surfactant mixture ${ }^{22}$. Recently the effect of surfactants on dye decolorization was studied and it was shown that positevely charged surfactant interacted with negatively charged dye and this interaction enhanced decolorization ${ }^{23}$. Interactions between anionic polymers and cationic micelles of Cetylthrimethyl ammonium bromide was studied and the interaction explained as electrostatical bounding of anionic head groups of polymer and positive head group of the micelle forming surfactant ${ }^{24}$. Aksu et al. (2010) have explained that the increase in number of ions (dye molecule) causing the competition for bind on surfactant ${ }^{12}$. The anionic dye and cationic surfactant (positive head group) associated because of electrostatic interactions but the limitation of surfactant concentration $(0.5 \mathrm{mM})$ resulted in decreasing the inteactions and also dye removal. The dye decolorization was maximum at low dye concentrations such as 50 and $100 \mathrm{mg} / \mathrm{L}$ dye concentrations at $\mathrm{pH} 5$ with 0.5 mM CTAB (Fig. 3).

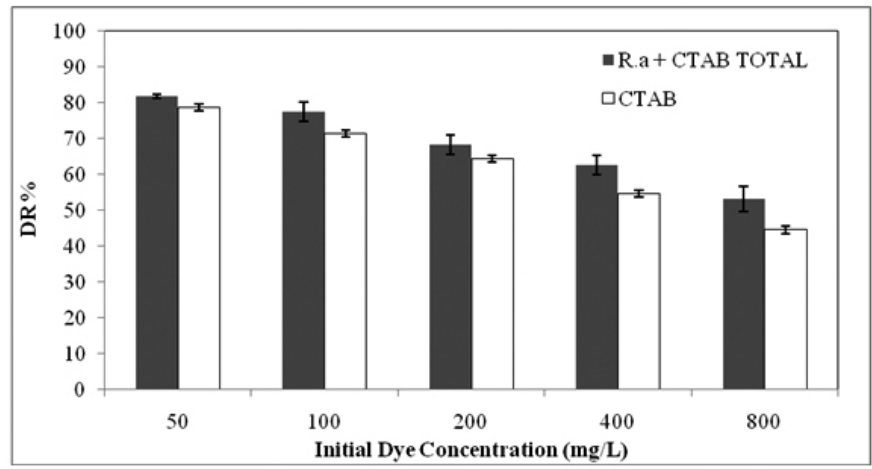

Fig. 3 The effect of initial dye concentration on dye removal (DR \%) with $100 \mathrm{mg} / \mathrm{L}$ initial Remazol Blue concentration at $\mathrm{pH} 5$ (R.a.: Rhizopus arrhizus; R.a +CTAB: fungus with $0.5 \mathrm{mM} \mathrm{CTAB}$; CTAB: $0.5 \mathrm{mM}$ Alkyl thrimethyl ammonium bromide without fungus; $\mathrm{T}: 30 \pm 1^{\circ} \mathrm{C}$; incubation period: 3 days).

\section{The effect of surfactant concentration and type on dye removal}

The effect of different cationic surfactant types (DTAB, CTAB and HTAB) on dye decolorization was tested with $100 \mathrm{mg} / \mathrm{L}$ dye concentration at $\mathrm{pH} 5$ and showed on Table 1 at the end of three days incubation period. All surfactants with fungus were higher dye removal activity than only surfactants. Maximum dye removal occured in the presence of HTAB with fungus. The augmentation of surfactant concentration resulted in increasing decolorization. Özdemir et al recently have reported that the cationic surfactant covered the zeolite adsorbent surface and resulted in increasing both anionic azo dye adsorption process and dye decolorization ${ }^{15}$. Choi et. al (2008) have shown that cationic surfactant and anionic dye formed a complex and the adsorbtion of dye on active carbon was enhanced. It was considered that surfactant enhanced the dye adsorption on the surface of fungus ${ }^{25}$.

The dye decolorization activity of only surfactant was very high at $1 \mathrm{mM}$ surfactant concentration of CTAB (92.1\%) and HTAB (97.1\%). The dye removal behavior of DTAB was different and lower than $\mathrm{CTAB}$ and $\mathrm{HTAB}$ Akisada et. al. (2007) have shown that the unusual behavior of critical micel concentration $(\mathrm{CMC})$ for alkylthrimethyl bromides depended on chain lenght difference ${ }^{26}$. CTAB, HTAB and DTAB have the same head group (which associated with dye) but different lenght of alkyl chain according to their linear formula. The hidrophobic tail of surfactants had major effect on the critical micelle concentration (CMC) ${ }^{27}$. Homberg et. al (2003) have reported that the augmentation of surfactants' alkyl chain lenght resulted in decreasing in CMC and the number of carbons in the alkyl chain effected CMC negatively ${ }^{28}$. The number of carbons in alkyl chain of DTAB, CTAB and HTAB were 12, 14 and 16 so HTAB had the minimum CMC value. It is assumed that the comparison of dye removal activity of these surfactants were correlated with their micellization. HTAB had the minimum CMC but maximum dye decolorization activity. The CMC of HTAB was near to $1 \mathrm{mM}$ surfactant concentration so the HTAB molecules become to form miscelles that removed dye molecules (97.1 $\%$ ) (Tablo 1). There was a relationship between CMC and dye removal activity of surfactant.

The results of this study supported that the positive head groups of cationic surfactants interacted with the anionic dye and this interaction encourged dye removal activity. The hydrophobic tail of surfactants (CTAB and HTAB) had major effect on micellization which enhanced removal of dye molecules.

The dye removal activity of fungus and DTAB and only DTAB were $71.3 \%$ and $13.2 \%$ in mollases medium with $0.5 \mathrm{DTAB}$ and $100 \mathrm{mg} / \mathrm{L}$ Remazol Blue concentration at $30^{\circ} \mathrm{C}$ in three days incubation period. The $\mathrm{CMC}$ of DTAB was the highest because of having lowest carbon number (12) in tail in compairing with $\mathrm{CTAB}$ and HTAB. It was assumed that in 0.5 and $1 \mathrm{mM}$ DTAB concentrations, DTAB did not form micelles and dye removal activity was the lowest one in comparison of CTAB and HTAB. Gül and Dönmez (2011) have shown that fungus and 1 mM DTAB removed $97.1 \%$ dye in five days ${ }^{16}$ but in this study fungus and $1 \mathrm{mM}$ HTAB removed $98.4 \%$ dye in three days. It was clearly that in the presence of HTAB the dye removal process was shortened and also the dye removal efficiency was raised.

Table 1. The effect of different cationic surfactant types (DTAB, CTAB and HTAB) on dye removal (DR \%) with $100 \mathrm{mg} / \mathrm{L}$ initial Remazol Blue concentration at pH 5 (R.a.: Rhizopus arrhizus; R.a +DTAB: fungus with $0.5 \mathrm{mM}$ DTAB; DTAB: $0.5 \mathrm{mM}$ Dodecylthrimethyl ammonium bromide without fungus R.a +CTAB: fungus with $0.5 \mathrm{mM} \mathrm{CTAB}$; CTAB: $0.5 \mathrm{mM}$ Alkylthrimethyl ammonium bromide without fungus; R.a +HTAB: fungus with $0.5 \mathrm{mM}$ HTAB; HTAB: $0.5 \mathrm{mM}$ Hegzadecylthrimethyl ammonium bromide without fungus $\mathrm{T}: 30 \pm 1^{\circ} \mathrm{C}$; incubation period: 3 days).

\begin{tabular}{|c|c|c|}
\hline & $\begin{array}{c}\text { DR\% } \\
(0.5 \mathrm{mM} \text { Surfactant })\end{array}$ & $\begin{array}{c}\text { DR\% } \\
\text { ( 1mM Surfactant })\end{array}$ \\
\hline R.a & 21.2 & 21.2 \\
\hline R.a + DTAB & 71.3 & 79.8 \\
\hline R.a + CTAB & 77.5 & 95.4 \\
\hline R.a + HTAB & 79.8 & 98.4 \\
\hline DTAB & 13.2 & 39.1 \\
\hline CTAB & 71.2 & 92.1 \\
\hline HTAB & 74.1 & 97.1 \\
\hline
\end{tabular}

\section{The effect of surfactants on fungal growth}

The effect of surfactants (DTAB, CTAB and HTAB) on microbial growth was tested as dry weight of culture in molasses media with $100 \mathrm{mg} / \mathrm{L}$ dye and $0.5 \mathrm{mM}$ and $1 \mathrm{mM}$ surfactant in $\mathrm{pH} 5$ at $30^{\circ} \mathrm{C}$ at the end of three days incubation period. The culture which grew in molasses media with $100 \mathrm{mg} / \mathrm{L}$ dye and without surfactant was used as blank. As seen on Figure 4, all surfactants inhibited fungal growth. The augmentation of surfactant concentration also decreased dry weight.

The minimum fungal growth occured in the presence of HTAB, although maximum dye removal have shown with HTAB. The microbial growth effected negatively, but dye removal effected positively. It was considered that in the system that contained both surfactant and fungus, the dye removal activity of surfactant was higher than fungus. 


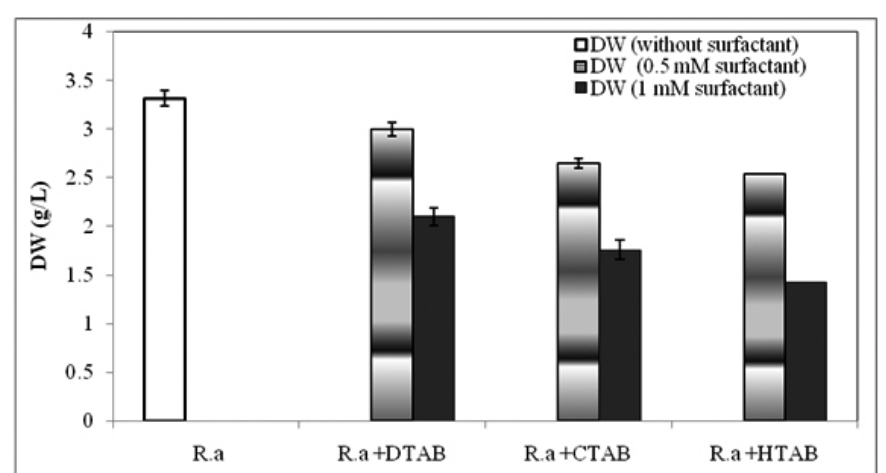

Fig.4 The effect of different cationic surfactant types (CTAB and HTAB) on dry weight (DW) of Rhizopus arrhizus (R.a.) with $100 \mathrm{mg} / \mathrm{L}$ initial Remazol Blue concentration at pH 5 (R.a +DTAB: fungus with 0.5 mM DTAB (Dodecyl thrimethyl ammonium bromide); R.a +CTAB: fungus with $0.5 \mathrm{mM} \mathrm{CTAB}$ (Alkyl thrimethyl ammonium bromide); R.a +HTAB: fungus with $0.5 \mathrm{mM}$ HTAB (Hegzadecyl thrimethyl ammonium bromide); T: $30 \pm 1^{\circ} \mathrm{C}$; incubation period: 3 days)

\section{CONCLUSION}

The results obtained from this study support that;

Maximum dye removal activity occured in the system contained both surfactant and fungus.

- The optimal conditions for dye decolorization were $\mathrm{pH}$ 5, low dye concentration like 50 and $100 \mathrm{mg} / \mathrm{L}$ in the system that contained both surfactant and fungus.

- Anionic dye and cationic surfactants interacted each other electrostatically and this interaction enhanced dye removal activity.

- The dye removal activity of only surfactant was related with CMC. The critical micelle concentration (CMC) depent on the number of carbons in the alkyl chain tail. The CMC of HTAB was the lowest because of having highest number of carbons in alkyl chain tail and maximum dye removal activity occured in the system contained both HTAB and fungus. This is the first study that shows the relationship between CMC and dye removal activity of surfactants.

- The use of surfactants in biological waste water treatment process will save energy and decreased energy costs (such as the required energy for treat techniques) by shortening incubation period.

It can be concluded that high amounts of dye can be effectively decolorize by the systems contained both surfactants and fungus. Decolorization technology of fungus and surfactants is a feasible approach to remove textile dyes from wastewater of textile industry. The use of surfactants that have the lowest CMC can essentially enhance the capacity of waste dye removal technologies.

\section{REFERENCES}

1. I.M. Banat, P. Nigam, D. Singh, R. Marchant. Bioresour. Technol. 58, 217-227, (1996)

2. B.E. Tastan, S. G. Ertuğrul, G. Dönmez. Bioresour. Technol. 101, 870$876,(2010)$

3. S.V. Mohan, K.K. Prasad, N.C. Rao, P.N. Sarma. Chemosphere.58, 1097$1105,(2005)$

4. E. Forgacs, T. Cserhati, G. Oros. Environ. Int. 30, 953-971, (2004)

5. F.P. Van der Zee, S. Villaverde. Water Res. 39, 1425-1440, (2005)

6. Z.Aksu, S. Tezer. Process Biochem. 36, 431-9, (2000)

7. T. O’Mahony, E. Guibal, J.M. Tobin. Enzyme Microbiol. Technol. 31, 456-63, (2002)

8. Z. Aksu, Ş.Ş. Çağatay. Sep. Purif. Technol. 48, 2435, (2006)

9. Z. Aksu, E. Balibek. J. Environ. Manage. 91, 1546-55, (2010)

10. A. Singh, J.D.V. Hamme, O.P. Ward. Biotechnol. Adv. 25, 99-121, (2007)

11. P. Becher. Emulsions, Theory and Practice, second ed. Reinhold Publishing, New York, 1965.

12. Z. Aksu, S. Ertuğrul, G. Dönmez. Chem. Eng. J. 158, 474-481, (2010)

13. B. Simoncic, J. Span. Dyes and Pigments. 36, 1-14, (1998)
14. C. Sudipta, D. S. Lee, M. W. Lee, S. H. Wooa. Bioresour. Technol. 100, 2803- 2809, (2009)

15. Ö. Özdemir, M. Turan, A. Turan, A. Faki, A. Engin. J. Hazard. Mater. 166, 647- 654, (2009)

16. Ü. D. Gül, G. Dönmez. Fresenius Environ. Bull. 20, 2677- 2683, (2011)

17. Z. Aksu, G. Dönmez. J. Chem. Technol. Biotechnol.75, 847-53, (2000)

18. Y. Fu, T. Viraraghavan. Bioresour. Technol. 79, 251- 26, (2001)

19. G. Dönmez. Enzyme Microbial. Technol. 30, 363-366, (2002)

20. A. Çelekli, M. Yavuzatmaca, E Beyazçiçek, H. Bozkurt, Fresenius Environ. Bull. 18, 994- 998, (2009)

21. B. Simoncic, J. Span. Dyes and Pigments. 36, 1-14, (1998)

22. M.N. Khan, A. Sarwar. Fluid Phase Equilibria. 239, 166-171, (2006)

23. M.N. Khan, S. Bhutto. J. Chil. Chem. Soc. 55, 170- 175, (2010)

24. C. Gamboa, R. Barraza, A. Folea. J. Chil. Chem. Soc. 49, 303- 306, (2004)

25. H-D Choi, M-C Shin, D-H Kim, C-S Jeon, K Baek. Desalination. 223 , 290-298, (2008)

26. H. Akisada, J. Kuwahara, A. Koga, H. Motoyama, H. Kaieda. Journal of Colloid and Interface Science. 315, 678- 684, (2007)

27. D. Myers. Surfactant Science and Technology. Third edition. John Wiley \& Sons Ltd, England, 140, 2006.

28. K. Homberg, B. Jönsson, B. Kronberg, B. Lindman. Surfactants and polymers in aqueous solution 2nd edition. John Wiley \& Sons Ltd, England, 259, 2003. 